\title{
TEACHING A LANGUAGE: OCCUPATIONAL WELL-BEING
}

\section{Yurko Nadiya ${ }^{1}$ \\ Styfanyshyn Iryna ${ }^{2}$}

DOI: https://doi.org/10.30525/978-9934-571-89-3_37

Language teaching is a demanding task. Teachers everywhere in the world are faced with similar challenges. The obstacles they encounter can arise from many directions and the many roles and responsibilities they have to maintain, they often feel accountability for more than they should. Teachers frequently decry the lack of time they are given to prepare, plan and execute all the tasks that are demanded of them [1].

Being a language teacher is not an easy job. They have a lot to learn about the technical side of language teaching. When it comes to the personal, emotional side of teaching, they are confident not to need any real training or work in this area. The point is that they are just not prepared for the long haul. This lack of preparedness, resulting in feelings of stress and low professional well-being, affects their teaching.

Therefore, the subject under research is the importance of teacher well-being in the language classroom and considering practical steps teachers can take to enhance their feelings of well-being.

\footnotetext{
${ }^{1}$ Lviv State University of Physical Culture, Ukraine

${ }^{2}$ Lviv State University of Physical Culture, Ukraine
} 
The first issue to be examined is the recent developments in thinking about occupational well-being. Many researchers view well-being as a context-free, global construct. However, other researchers emphasize the importance of assessing wellbeing in specific contexts, most notably at work. Job specific conceptualizations of well-being differ from study to study [2].

Occupational (or career) wellbeing refers to feeling good about the work you do. It has many facets, including achieving a balance between work and leisure, maintaining positive relationships with colleagues, managing workplace related stress, the safety of the workplace environment and the climate of the worksite [3].

Occupational well-being involves the ability to achieve a healthy work-life balance, manage workplace stress and build relationships with bosses and coworkers while integrating the commitment to your occupation into a lifestyle that is both satisfying and rewarding [4].

We often think that work and life should be separate. We go to work, work hard and then come home and want to switch off. Instead of thinking that life and work need to be separate, we need to think of our life as one whole, and work fits into this, not the other way around. The reality is we have a life and work fits into this, however the problem is when we get home we do not have any clear mental and emotional boundaries to separate them. It is through establishing some simple boundaries that we can better create work-life balance. In a nutshell, we need to schedule our priorities not prioritize what is on our schedule.

The focus of our attention is also upon the concept of mindsets, specifically in learning and teaching activity. At its simplest, the concept of mindsets is based around two distinct worldviews. Some people tend to believe in the fixed nature of humans, that we are all essentially born with certain talents and characteristics and there is little we can do to change them. In contrast, other people see more potential for growth and change; if we work hard enough at something we will eventually succeed. Of course, people may have different mindsets for different areas of their lives, but in education, most of the discussion around mindsets has concentrated on ideas of natural ability and the power to grow through sustained, focused efforts. As far as language teaching is concerned, it is can be arguable that an understanding of our teaching mindsets can help our overall sense of professional well-being.

One of the most cited reasons for the uniqueness of language teachers is that of the subject matter, including both the unity and content of medium, and the variety of the content [5]. Moreover, some practitioners claim making an extra effort while preparing and delivering their lessons, since they must focus on how they were saying what they said. This fact may also become a factor adding strain and raising the anxiety levels of teachers, since they feel constantly evaluated.

Teaching is about so much more than the simple transfer of mental knowledge but the interpersonal side to teaching receives relatively little attention, leaving teachers feeling that they lack control or the power to change things. While many teachers are very supportive of growth mindsets for academic learning, they can have very fixed mindsets when it comes to the stressful aspects of teaching. One of the major causes of stress for teachers is the feeling of being pulled in several directions, always under 
pressure to meet deadlines, of simply not having enough hours in the day. However, teachers often see poor time management as a personality feature, and something they cannot change.

On the grounds of the mentioned above, it is reasonable to suggest some practical steps teachers can take to reduce feelings of stress, to feel more positive and enthusiastic about their work, to essentially change themselves.

The first step to building teacher wellbeing is to understand the nature of wellbeing. It is not static or something you achieve, it is something you manage moment to moment along a continuum of emotions. It requires awareness of emotions and the decisions we make to manage these emotions.

The next is to acknowledge the challenges of teaching. Teaching is tough and sometimes the rewards do not match the challenges. We need to allow time and space for debriefing with a recreational whinge, but we must not live there, we must express it and move it.

Another essential step to support teacher wellbeing is to encourage the social and emotional development. Teacher training is very good at giving us skills in planning, assessing and reporting yet falls short in preparing us with skills to better understand and manage the social and emotional energy we use on a daily basis. Staff training must incorporate personal development as much as it does professional development.

One of the toughest aspects of teaching are the expectations we place on ourselves to perform, and the tasks required often seem endless. The antidote to this cycle is self-compassion, i.e., nurturing yourself, establishing healthy boundaries and modelling self-care. By cultivating compassion we gift ourselves fresh perspectives on how to solve challenges, think more freely and have more energy to give our students. Overall, self-compassion is about being mindful enough to make small choices that have a positive impact on the general wellbeing. This may mean going for a walk, reading inspiring material or laughing with friends. Self-compassion requires us to observe and control fearful or negative thoughts and reframe perspectives to acknowledge ourselves as worthy of the same love and care we so readily give to others.

Consequently, it can be concluded that the more we restore, the more we have to give and prouder we become of our own contribution in the world. Great teachers know how to set boundaries that include strategies for their own self-care. Thinking about oneself is not selfish. They know that in order to be their best for others, and be able to continue to give to others, they must know when and how to restore their own wellbeing. The next step to this is that modelling self-care is a powerful way of showing not only colleagues but also the students, how they too can better manage their own wellbeing. Professional well-being makes teachers perform at a higher level, and results in improved learning outcomes.

\section{References:}

1. Dussault, A. (2018). 2018's top 8 classroom challenges, according to teachers. Classcraft. Retrieved from: https://www.classcraft.com/blog/features/8-teacher-challenges-2018/ (accessed April 02, 2019). 
2. Schultz, M. L. (2004). Occupational well-being: the development of a theory and a measure. K-State Research Exchange. Retrieved from: http://krex.k-state.edu/dspace/bitstream/handle/2097/ 746 (accessed April 02, 2019).

3. Occupational Wellbeing. (2017). Wellbeing Therapy Space. Retrieved from: http://www.wellbeingtherapyspace.com.au/occupational-wellbeing/ (accessed April 02, 2019).

4. What is occupational well-being? (2016). Ou Rec Well. Retrieved from: https://ourecwell.wordpress.com/2016/10/24/what-is-occupational-well-being/(accessed April 02, 2019).

5. Borg, S. (2006). The distinctive characteristics of foreign language teachers (2017). Language Teaching Research. SAGE journals. Retrieved from: https://journals.sagepub.com/doi/10.1191/ 1362168806lr182oa (accessed April 02, 2019). 